\title{
ICTs and Music in Generic Learning Disabilities
}

\author{
https://doi.org/10.3991/ijet.v12i04.6588 \\ Paraskevi Theodorou \\ National Center for Scientific Research "Demokritos", Agia Paraskevi, Attica, Greece \\ van 4 . theodoroudgmail.com \\ Athanasios S. Drigas \\ National Center for Scientific Research "Demokritos", Agia Paraskevi, Attica, Greece \\ dr@iit.demokritos.gr
}

\begin{abstract}
The purpose of this paper is to review the most representative studies of the last decade (2006-2015) which deal with the combination of technology and music and concern individuals with Generic learning disabilities. Particularly, the areas of needs in this paper are divided to the following categories: Depression/ disruptive behavior, Down syndrome, Intellectual disabilities, Cerebral palsy and Severe/Profound disabilities. It is also underlined the important role of Information and Communication Technologies (ICTs) and digital music tools in promoting musical participation and assisting students with the pre-referred disabilities.
\end{abstract}

Index Terms-Depression/ disruptive behavior, Down syndrome, Intellectual disabilities, Cerebral palsy, Severe/Profound disabilities, melotherapy

\section{Introduction}

Concerning depression and disruptive behaviors, melotherapy is an alternative therapy, psycho-preventive which emphasizes in the therapeutic value of music [1]. The last decades there is a major increase of music technologies which are useful for clinical settings including computer based applications, digital interface and assistive devices (computer based application like "voice output communication aids VOCA"). These applications address to adults and adolescents with behavioral disorders [2]. The following research analyses the benefits of Music in the improvement of emotional intelligence, behavior and school performance through an experience with $4^{\circ}$ ESO (the Spanish equivalent to England's Year 11) student group [3]. Nowadays, people are constantly living a stressful life for a brighter future, which consequently causes physical and mental illness. Therefore music therapy is an effective solution to cure these mental illnesses [4]. Music therapy is ideal for students with emotional and behavioral disorders (EBD) [5]. Wiimprovisation process of using Nintendo Wiimotes as Virtual instruments linked to a musical sound system within the framework of Group Music Therapy sessions can offer psychodynamic mediation for patients [6]. 
Furthermore for Down Syndrome Children (DS), there is an introduction of "SynMax" which is mathematics computer application software to learn the concepts of numbers [7]. An alternative teaching tool with great popularity is educational courseware. The purpose of the study is to review the existing courseware designed for Down syndrome children in terms of their design techniques and content [8].

Dealing with intellectual disabilities, there is an emphasis on the role of a digital 'music jamming' tool (Jam2jam) in promoting musical participation for these people and enables individual or collective improvisation. It also describes the participants' orientations to music technology [9]. Following, the pedagogical and social potential of emerging technologies is explored, in particular the iPod, in facilitating the learning of young Australians with severe intellectual, physical and social disabilities [10]. Also, the evaluation procedure for teaching three students with developmental disabilities so as to listen to music and independently operate a portable multimedia device is examined [11]. The focus of this paper is to present the first set of test results generated by the Music Therapy Logbook Proof of Concept Study [12]. Special education for people with Disability, Environmental Education and the Human Computer Interaction (HCI) with the use of Music Paint software are presented in the next paper [13].

Next is presented an Augmented Reality Musical System for music therapy in which, a system of colored cards with graphic symbols replaces the music keyboard for cases with Cerebral Palsy [14]. Also a set of multimedia exercises were used in order to possibly improve the mathematical skills of pupils with mental retardation and cerebral palsy [15]. Due to the demand of an advanced treatment especially for children with cerebral palsy a sophisticated device has been constructed: the Robot Piano Player with tele-operated control [16].

There is an interface which makes use of touch like vibrations in order to encourage children with severe or profound cognitive, sensory and physical impairments to move, using V-Sense as a vibrotactile interface [17]. The development of V-Sense, an "invisible" vibrotactile interface, motivates children with multiple disabilities to move their arms by using vibrations and exploring the saltation perceptual illusion [18]. An original research project (PROMISE) examines the Provision of Music in Special Education in schools for pupils with severe or profound disabilities [19]. Where electronic music technology is being used in therapy, the dominant application is with equipment which uses specialist input devices such as single switches and sensors requiring only gesture rather than physical contact [20]. A revolutionary use of humanoid robot called NAO is very effective for children with autism [21]. Furthermore there is a review of the studies which used microswitches and speech output systems with the aforementioned people during the 1986-1999 period [22]. A qualitative study collected data is provided by music therapists experienced in using electronic equipment using MIDI [23]. 


\section{Generic Learning Disabilities}

\subsection{Depression/ disruptive behavior}

Nowadays music therapy is applied very successfully as a note healing method for various affections like stress, nervousness, anxiety, physical and psychological asthenia, headaches, migraines, insomnia, depression, high blood pressure, palpitations, arrhythmia, dyslexia, Parkinson disease, Alzheimer's disease, cardiac insufficiency etc [1]. The techniques of melotherapy are divided into two parts, the passive and the active one. The passive method refers to listening to classical music. The active one has several techniques like the Improvisation, the Recreational and the Compositional method. Nowadays, online sources are used in melotherapy (ICT). An experiment has been done in a special needs school in order to establish ways of communication for improving aggressiveness. In conclusion, applying the active methods of melotherapy has led to outline an innovative methodological model [1].

Here there is an introduction of "voice output communication aids - VOCA") [2]. These applications address to adults and adolescents with behavioral disorders concerning developing social skills, group decision-making, and learning disabilities. For students with multiple disabilities, the use of VOCA allows for independent participation in group music making. There are different cases using VOCA. The first case is with an adolescent with complex needs in a joint music/speech therapy group. The next case refers to the use of switches to enable inclusion in the school band and the last case refers to adolescents with sensory impairments. Other cases concern a child with burns, an elderly woman receiving radiotherapy and an adult in the palliative stages of cancer treatment. Generally music technologies can maximize the proportion of music therapy programs applied to everyone from infants to elders [2].

This research emphasizes a lot in Emotional Intelligence (E.I.) of a group of students and their Intelligent Quotient (I.Q.) [3]. Also examines students' correspondence and innovative abilities in music classes. The aim is to improve emotional competence and consequently academic performance. The research includes seven demotivated participants with disruptive and antisocial behaviors. The main purpose is to analyze what is the starting point of this student group (deficits, motivations) and enhance their capabilities with the use of music benefits. In short, the goal of this study is to specify if there can be an improvement in the academic performance and the behavior of students' with emotional problems are the first cause of scholar failure (Lucrat, 1997; Jadue, 2002) [3].

Music therapy is an effective solution to cure mental illnesses caused by stress [4]. Actually Music Therapy via wireless distribution (MITWD), is a concept that combines musical tele-therapy with the benefits of security camera and technology in order to prevent and cure the symptoms and illnesses caused by stress. In particular the appropriate type of music is exceptionally beneficial to cure insomnia, anxiety, depression etc. What is more, music can improve career performance, increase concentration and addresses to physical, emotional, cognitive and social needs of all ages. It also leads to crime prevention. Individualized Music Therapy Assessment Profile (IMTAP) which helps the therapist understand better the patient offers a higher quali- 
ty of results. All in all, the musical tele-therapy is not only an innovative and splendid concept, but it is also a safe method for healing as it is retrieved from nature [4].

The objective of this work is the impact of music therapy to students with EBD and the proposal of a model of music therapy for them in a psychoeducational setting [5]. These mentally imbalanced students have short attention spans, difficulties relating to people, low self-esteem and family problems. They are generally easily frustrated. Therefore music therapy contributes positively to communication, behavior and selfconfidence. Music therapy programs are applied in schools and residential settings using reading comprehension, phonetics and meaning interpretation. Finally a combination of music and technology is a non-invasive medium that enhances selfexpression, self-esteem, motor skills, coordination, socialization, creativity, inventiveness, independence and success. Music is a great reinforce and motivator for human beings [5].

As music therapy is an old-age technique of therapeutic practice which uses music as a communication go between patients and therapists is easily applicable to users [6]. Greek Plato and ancient Chinese healers endorsed this effective technique ages ago. Wiimprovisation introduces Wiinotes as virtual instruments in a move traditional musical mediation therapy. There are references to related work, experimental conditions and results. Future work will focus on assessing the therapeutic potential of our platform's personalization features in a controlled experiment [6].

\subsection{Down syndrome}

The Down Syndrome children use the same learning strategy as the normal ones but they learn more slowly [7]. The use of computer base application (SYNMAX) which the children can interact with the material is a great aid. SYNMAX, based on dual coding learning theory, schema learning theory, is the first initiative of development of a learning tool for DS children in Malaysia aimed at enhancing their numeracy skills. There are basically three activities: "Learning", "Counting" and "Matching". On the whole the results indicate that the children accept the application and follow the instructions given. For a more pleasant approach the application could replace the existing background music with nursery rhymes or songs [7].

The particular courseware implemented different courseware design techniques with different target subject [8]. The testing result of MEL-SindD has proven that scaffolding method can increase children's confidence level. Children participated actively when using the courseware. The research took place in Malaysia in the recent years. Also Synmax is a multimedia courseware that focuses on numerical skills among Down Syndrome children. Finally there is a comparison among different courseware in terms of the design techniques and content, so that future improvements and suggestions can be made [8].

\subsection{Intellectual disabilities}

The research for this paper took place in two day centers in Brisbane, Australia, for adults with significant intellectual disabilities [9]. Jam2jam is a tool based on genera- 
tive principles and thus is underpinned by an algorithmic music system which itself exerts at least partial control in the development of a work. With the former the user is allowed to generate a musical output, which is in line with the particular style chosen and without needing the traditionally required performance skills. Knowledge and techniques associated with the rules of different instrumental practices and musical style is not an obstacle. The aim of this survey was the participatory possibilities of the jam $2 \mathrm{jam}$ tool for people with intellectual disabilities based on the theoretical and conceptual considerations outlined above. Finally, questions are raised of the human-technology interrelations [9].

Epistemologically, this research finds its conceptual framework within constructivism [10]. As far as methodological perspective is concerned qualitative approach was conducted. The iPods, which focus on utilitarianism and non-constructivism, have significant advantages such as multi-media potentialities, flexibility and easy portability. The iPods were placed in classrooms to be used with and by students, under the supervision of teachers using music, photographs, PCS (Picture Card Symbols), videos, spoken word and social scripts in video, textual and slide show formats. All in all podcasting and webcasting introduced culturally diverse musical styles. In the future, the school is looking forward to integrate the program with the use of electronic whiteboards across the school [10].

Mainly the next method includes the operation of an iPod Touch while listening to music [11]. It was divided in the following parts: participants, settings, materials, stakeholder questionnaire, task analysis, video module, experimental design, baseline, video-modeling, fading, follow-up, inter-observer agreement and procedural integrity. The three participants had different performance results which were evaluated accordingly. In conclusion the use of an iPod Touch for leisure purposes as well as for listening to music and using multimedia is a very effective tool [11].

Two hypotheses were evaluated by the music therapist [12]. Firstly, if therapist's changes in her tempo were affecting patients' tempo and secondly, whether her musical interventions were helping the patient reduce habituated, rhythmic patterning. The Music Therapy Logbook is the first to apply computational music analysis to recordings of individual music therapy sessions with a combination of percussion instruments and a MIDI piano. Music therapy was illustrated to the high level expertise team via audio and video material so that music therapists could establish the types of music they want to evaluate. Conclusively computational music analysis manages to identify and map the duration of a patient's improvisations on three different acoustic percussion instruments whilst a therapist plays a MIDI piano [12].

Here is described a pilot use of seven students with disability [13]. In particular, the Music Paint Software and Human Computer Interaction (HCI), developed by the authors of the Dept. of ECE (Thessaloniki, Greece) proposes effective ICT integration to a goal-directed instruction for students with Mild and Moderate mental retardation. The results showed the positive potentiality of the Music Paint to enhance the accessibility of students with disability to Environmental Education opportunities, improving accessibility in the educational settings [13]. 


\section{$2.4 \quad$ Cerebral palsy}

In this article an experiment is conducted addressing to a child with cerebral palsy [14]. The therapist can print cards of different sizes and place them in various ways, according to the desired motor exercise. The objective of this effort is not only to replace but to extend the conversional process of rehabilitation. There is a great simulation of sounds of various musical instruments in order to help users to create melodies and save them. There was an evaluation of the prototype and clinical use. On the overall, the results show that this system has therapeutic interventions and includes learning of motor, psychological, social and musicality [14].

IT in general and internet in particular may well provide a new paradigm so that communication and education approach is more complex than ever before [15]. A case study is presented where a set of multimedia exercises were used in order to possibly improve the mathematical skills of pupils with mental retardation and cerebral palsy. Music and multimedia together with exercises and games is a great learning method for children with special needs. All in all the above mentioned multimedia exercises, help children acquire basic learning skills, increased self-determination, become more autonomous and acquire integration skills [15].

This particular research focuses on investigating communication technologies that encourage interaction between children with severe physical disabilities and robot playmates [16]. These augmentative communication devices motivate children to play, learn and interact through their surroundings. Especially children with physical disabilities such as cerebral palsy have problems using their hands. Therefore this paper emphasizes on the importance of using the Boardmaker ${ }^{\circledR}$ Plus!, which is a special needs education software so as to provide access to toys for children with physical disabilities. Conclusively, piano playing robotic playmate is essential for children with physical disabilities in order to learn and communicate with their emotions [16].

\subsection{Severe/Profound disabilities}

The introduction on a particular interface is the completion of the Sinasense project, which is a motion-based interface that serves as an educational application for children [17]. This interface fights against severe impaired peoples' isolation and limitation in their interactions with the surrounding world. The main focus of research on Vibrotactile interfaces is about visually impaired users. It has been used to face saltation illusion, elbow and shoulder flexion. Finally the goal is whether the use of vibrotactile information motivates the user's movement concerning his arm or forearm [17].

Whereas Vibrotactile interfaces work for users with sight or hearing impairments, there are hardly any interfaces for users with multiple disabilities [18]. The introduction of V-Sense, an "invisible" vibrotactile interface, motivates children with multiple disabilities to move their arms. The initial experience of 5 children for 7 weeks is described in this study. V-Sense is an extension of Sina Sense, a previous vibrotactile interface. The participants' evaluation is really difficult because they have unique 
intellectual, behavioral, physical and sensory conditions. In conclusion the user's learning and progress is very slow, so there has to be a continuous testing of the interface [18].

This work searches the distinctions and relationships between music education, music therapy and music as a vehicle for other forms of learning, occupation, development and engagement [19].Furthermore it examines the awareness and preparation of professionals in schools to explore these issues from an informed perspective. Therefore several professors present and expand on the key findings from their recent research project 'PROMISE' which examined the Provision of Music in Special Education and particularly in schools for pupils with severe or profound and multiple learning disabilities (SLD and PMLD). Eventually as music promotes body awareness and movement, it also explores the boundaries between education and therapy [19].

Although assistive technologies have enabled access to work and leisure pursuits for severe disabled people, there is limited published relevant information about music technology for therapeutic applications [20]. There were questionnaires with no reference to the definition of music technology. The findings show willingness and positive attitudes on the parts of music therapists. In electronic music technology for therapeutic reasons, the applicable equipment uses specialist input devices such as single switches and sensors requiring only gesture rather than physical contact. Further exploration is warranted into the existent application of electronic music devices in clinical music therapy and in particular those technologies using alternative control interfaces [20].

According to statistics and calculations pupils with intellectual disabilities is stable but there has been a rise in the number of children with profound and multiple disabilities (PMLD) [21]. Nevertheless it has to be proved that it will be the same with pupils with PMLD. NAO which is a humanoid robot is introduced, so as to be used as an educational tool. It is manufactured with a wide range of behaviors including walking, standing up, sitting down, recognizing speech and objects as well as producing speech from text, playing sound files and favorite pieces of music could be transformed into wav files and included as a complete instruction in Choregraphe. One of aims of complex behaviors was to enable the robot to be controlled remotely by microswitches and a joystick. Observations of engagement, assistance and goal achievement remained at the same level [21].

There are seven studies with on microswitch activating different stimuli, two studies with one microswitch connected to tape-recorded verbal messages, speech output systems, studies using one of a few messages and studies using larger numbers of messages [22]. Different forms of stimulation are used: songs, music, video scenes and a vibrating pad. In conclusion there are pros and cons with the use of microswitches but there are much more advantages for people with severe/profound, intellectual or multiple disabilities [22].

Since there is a growing demand for music therapists, these electronic music tools offer an objective assessment of their role in music therapy, but guidelines for their application in therapy are lacking [23]. Using MIDI interesting research questions occur and the findings propose a five-step treatment model when using technologies with people with complex needs. Clinical indicators include complex physical and 
sensory disabilities, motivational problems and specific needs pertaining to expression of identity. Eventually the model emphasizes the importance of positioning technology and establishing cause and effect when working with this population, as well as specific skills required of the therapists when using such tools [23].

\section{Conclusions}

The results of the current study are encouraging and there is a general consensus that ICTs play a significant role in enforcing learning and life skills programs of students with special educational needs. Research has shown that extensive use of computer software has contributed a lot in the reaction between a therapist and a patient in music therapy sessions especially with acquired brain injury patients [12]. Additionally a revolutionary use of robots to engage children with disabilities, especially autism has been proved very effective [21]. In conclusion, music technology has a precious role within therapeutic horizons and much better potential than it has been identified. Therefore there are several fields that require further research.

\section{$4 \quad$ References}

[1] NEDELCUȚ, N., POP, C. G., BORZAN, C., "A model of approaching melotherapy through on-line sources- An alternative to the treatment of children with communicative deficiencies". Department of Continuing Education and Distance Learning Academy of Music Gheorghe Dima.

[2] Magee, W. L., Bertolami, M., Kubicek, L., LaJoie, M., Martino, L., Sankowski, A., Zigo, J. B. "Using Music Technology in Music Therapy With Populations Across the Life Span in Medical and Educational Programs. " Music and Medicine, 3(3), pp. 146-153 (2011) https://doi.org/10.1177/1943862111403005

[3] Fernández, R. C., Vázquez, M. D., \& Ferreiro, F. J. "Music Therapy in Adolescent Disruptive Behaviour". Procedia - Social and Behavioral Sciences, 132, pp. 608-614 (2014) https://doi.org/10.1016/j.sbspro.2014.04.361

[4] Prashyanusorn, P., Pavaganun, C., \& Yupapin, P. P. "Music therapy via wireless internet for stress symptom and crime prevention". Procedia - Social and Behavioral Sciences, 2(1), pp. 68-73 (2010) https://doi.org/10.1016/j.sbspro.2010.01.015

[5] Sausser, S., \& Waller, R. J. "A model for music therapy with students with emotional and behavioral disorders". The Arts in Psychotherapy, 33(1), pp. 1-10, (2006) https://doi.org/10.1016/j.aip.2005.05.003

[6] Benveniste, S., Jouvelot, P., Lecourt, E., \& Michel, R. "Designing wiimprovisation for mediation in group music therapy with children suffering from behavioral disorders". Proceedings of the 8th International Conference on Interaction Design and Children - IDC '09, Como, Italy (2009) https://doi.org/10.1145/1551788.1551793

[7] Shafie, A., Wan Ahmad, W. F., Mohd., N., Barnachea, J. J., Taha, M. F., \& Yusuff, R. L. "SynMax": A Mathematics Application Tool for Down Syndrome Children. Advances in Visual Informatics, pp. 615-626 (2013).

[8] Kien Heng, Ng., Aryati, B., Azizah, A. R. "A Review on Courseware for Down Syndrome Children". Journal of information systems research and innovation, pp. 56-65 (2008) 
[9] Adkins, B., Summerville, J., Knox, M., Brown, A. R., \& Dillon, S. "Digital technologies and musical participation for people with intellectual disabilities." New Media \& Society, 15(4), pp. 501-518 (2012) https://doi.org/10.1177/1461444812457338

[10] Marks G and Milne G., "iPOD therefore I can: Enhancing the learning of children with intellectual disabilities through emerging technologies". Proceedings of ICICTE 2008, University of Ballarat, Australia

[11] Kagohara, D. M., Sigafoos, J., Achmadi, D., Van der Meer, L., O’Reilly, M. F., \& Lancioni, G. E. "Teaching students with developmental disabilities to operate an iPod Touch ${ }^{\circledR}$ to listen to music. " Research in Developmental Disabilities, 32(6), pp. 2987-2992 (2011) https://doi.org/10.1016/j.ridd.2011.04.010

[12] Streeter, E., Davies, M. E., Reiss, J. D., Hunt, A., Caley, R., \& Roberts, C. " Computer aided music therapy evaluation: Testing the Music Therapy Logbook prototype 1 system." The Arts in Psychotherapy, 39(1), pp. 1-10 (2012) https://doi.org/10.1016/j.aip. 2011.11.004

[13] Hadjileontiadou, S. J., Plastra, E., Toumpas, K., Kyprioti, K., Mandiliotis, D., Barroso, J., \& Hadjileontiadis, L. J. "On Enhancing Disabled Students' Accessibility in Environmental Education Using ICT: The MusicPaint Case. " Lecture Notes in Computer Science, pp. 325-336 (2014) https://doi.org/10.1007/978-3-319-07440-5 30

[14] Correa, A. G., Ficheman, I. K., Nascimento, M. D., \& Lopes, R. D. "Computer Assisted Music Therapy: A Case Study of an Augmented Reality Musical System for Children with Cerebral Palsy Rehabilitation." 2009 Ninth IEEE International Conference on Advanced Learning Technologies (2009). https://doi.org/10.1109/ICALT.2009.111

[15] Reis, M.G. A. D., Cabral, L., Peres, E., Bessa, M., Valente, A., Morais, R., Soares, S, Baptista, J., Aires, A., Escola, J. J., Bulas-Cruz, J. A. \& Reis, M. J. C. S."Using Information Technology Based Exercises In Primary Mathematics Teaching of Children With Cerebral Palsy and Mental Retardation: A Case Study." TOJET: The Turkish Online Journal of Educational Technology: issue 3 vol. 9, pp. 106-116 (2010)

[16] Miyako, J., Terrence, Trapp, Naquasia, J., Douglas, B., and Ayanna, M.H. "Engaging Children with Severe Physical Disabilities via Teleoperated Control of a Robot Piano Player" 12th International ACM SIGACCESS Conference on Computers and Accessibility Orlando, FL, USA pp. 25-27 (2010)

[17] Manresa-Yee, C., Morrison, A., Larsen, J. V., \& Varona, J. "A Vibrotactile Interface to Motivate Movement for Children with Severe to Profound Disabilities." Proceedings of the XV International Conference on Human Computer Interaction - Interacción '14 (2014) https://doi.org/10.1145/2662253.2662263

[18] Manresa-Yee, C., Morrison, A., \& Muntaner, J. J. "First Insights with a Vibrotactile Interface for Children with Multiple Disabilities." Proceedings of the 33rd Annual ACM Conference Extended Abstracts on Human Factors in Computing Systems - CHI EA '15 (2015)

[19] Ockelford, A., Welch, G. and Zimmermann, S. "Music education for pupils with severe or profound and multiple difficulties - current provision and future need". British Journal of Special Education Vol 29, No. 4, pp 178-182 (2002) https://doi.org/10.1111/1467$\underline{8527.00266}$

[20] Magee, W.L. "Electronic technologies in clinical music therapy: a survey of practice and attitudes." Technology and Disability, 18(3), pp. 139-146 (2006)

[21] Standen, P., Brown, D., Roscoe, J., Hedgecock, J., Stewart, D., Galvez Trigo, M. J., \& Elgajiji, E. " Engaging Students with Profound and Multiple Disabilities Using Humanoid Robots". Lecture Notes in Computer Science, pp. 419-430 (2014) https://doi.org/10.1007/978-3-319-07440-5 39 
[22] Lancioni, G. E., O'Reilly, M. F., \& Basili, G. "Use of microswitches and speech output systems with people with severe/profound intellectual or multiple disabilities: a literature review." Research in Developmental Disabilities, 22(1), pp. 21-40 (2001) https://doi.org/10.1016/S0891-4222(00)00064-0

[23] Magee, W. L., \& Burland, K. "An Exploratory Study of the Use of Electronic Music Technologies in Clinical Music Therapy." Nordic Journal of Music Therapy, 17(2), 124141 (2008) https://doi.org/10.1080/08098130809478204

\section{Authors}

Theodorou Paraskevi has a MA in Special Education and a Msc in Digital Systems and Telecommunications. She is a Teaching Professional in Information and Communication Technologies (ICTs). She is also a Teacher of Music playing and the Theory of music. She has participated in various research projects regarding the use of ICTs in Special Education (vantheodorou@sch.gr, van4.theodorou@gmail.com).

Athanasios Drigas is a Research Director at IIT-N.C.S.R. Demokritos. He is the Coordinator of Telecoms Lab and founder of Net Media Lab since 1996. From 1990 to 1999 he was the Operational manager of the Greek Academic network. He has been the Coordinator of Several International Projects, in the fields of ICTs, and eservices (e-learning, e-psychology, e-government, e-inclusion, e-culture etc). He has published more than 270 articles, 7 books, 25 educational CD-ROMs and several patents. He has been a member of several International committees for the design and coordination of Network and ICT activities and of international conferences and journals. Also he has accepted several distinctions for his work (articles, projects, patents) (dr@iit.demokritos.gr).

Article submitted 23 December 2016. Published as resubmitted by the authors 17 February 2017. 